Fourth International Conference on Sustainable Construction Materials and Technologies http://www.claisse.info/Proceedings.htm

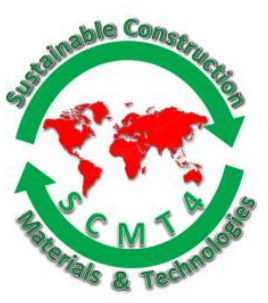

SCMT4

Las Vegas, USA, August 7-11, 2016

\title{
Utilization of Steel Slag in Concrete as Coarse Aggregate
}

\author{
Tarek U. Mohammed ${ }^{1 a}$, Md N. Rahman ${ }^{1 b}$, Aziz H. Mahmood ${ }^{1 c}$, Tanveer Hasan1 ${ }^{1 d}$, and \\ Shibly M. Apurbo ${ }^{1 \mathrm{e}}$
}

${ }^{1}$ Department of Civil and Environmental Engineering, Islamic University of Technology (IUT), Gazipur 1704,Bangladesh ${ }^{1 a}$ Email: <tarek@iut-dhaka.edu>, ${ }^{1 b}$ Email:〈nafi@iut-dhaka.edu>, ${ }^{1 c}$ Email: <hasancee@iut-dhaka.edu>, ${ }^{1 d}$ Email: $\langle$ tanveer.cee10@gmail.com>,

${ }^{1 e}$ Email:<apurbo@iut-dhaka.edu>

\begin{abstract}
This study has been conducted to explore the possibility of utilization of steel slag in concrete as coarse aggregate. After collection of steel slag aggregate from a local steel manufacturing company, the steel slag aggregate was separated into lightweight (SL), heavyweight (SH), and mixed (SM) slag aggregates. The aggregates were tested for different physical properties as well as mechanical properties by preparing cylindrical concrete specimens $(100 \mathrm{~mm}$ by $200 \mathrm{~mm})$ with different W/C ratios, cement contents, and sand to aggregate volume ratios. Total eleven cases for slag aggregates and five cases for brick aggregates were investigated. The concrete specimens were tested at 7,28,60 and 90 days. Also, ultrasonic pulse velocity (UPV) test was conducted prior to crushing of the specimens for evaluation of compressive and tensile strengths. For comparison, similar investigations were also carried out on brick aggregate commonly used in Bangladesh.
\end{abstract}

Experimental results show that slag aggregates absorb less water compared to the brick aggregates. The compressive strength of concrete made with mixed slag aggregate is similar or better than that of concrete made with brick aggregate. Concrete made with heavyweight slag aggregate gives more compressive strength than other aggregates. Relationships between compressive strength and modulus of elasticity of concrete, compressive strength and tensile strength of concrete are proposed for different slag aggregates.

\section{INTRODUCTION}

Bangladesh has very limited availability of natural stones. Due to this reason, brick aggregate is the main building material for the country's construction industry. But brick industries are associated with a lot of negative environmental impacts. Therefore, it is necessary to find possible alternative resources that can be used as coarse aggregate in construction works. An extensive study on the recycling of demolished brick concrete as coarse aggregate was carried out for the sustainable use of construction materials in Bangladesh [Mohammed et al 2015]. Investigations on other possible alternatives, such as steel slag may be conducted.

The demand of steel in Bangladesh is estimated at about 3 million metric ton with $2.5 \%$ growth in each year. During production of steel, a significant portion of by-product (5-6\% of total weight of steel 
production) is produced and these are classified as furnace steel slag (produced during melting of scrap and sponge iron and it becomes in lumped form after cooling in a slag pot, it is rich in silicon oxide, iron oxide and manganese oxide), process slag (produced in ladle refining furnace where $\mathrm{CaO}$ and other necessary ingredients are added to fix required chemical parameters of steel, it is produced in finer form and rich in calcium oxide, silicon oxide, magnesium oxide and iron oxide) and flue dust (collected from the smoke generated during melting of scrap and sponge in blast furnace, it is rich in carbon and zinc). Ground granulated blast furnace slag (GGBFS) can be used as a mineral admixture in cement. Also, furnace slag can be used as coarse aggregate for making concrete as well as aggregate in asphalt paving roads [Dieu and Lunagaira 2015]. Flue dust can be used in many industrial products as the source of carbon and zinc and also in fertilizer production [Yi et al 2012]. The use of slag as aggregate will reduce the need for virgin aggregate, energy required and pollutant emissions during the mining, processing, and transportation of materials. Investigations on the utilization of furnace slag as coarse aggregate in concrete have been conducted by many researchers as partial replacement or full replacement of stone coarse aggregate by slag aggregate [Maslehuddin 2003, Kothai and Malathy 2013, Sandhu et al 2015, Nadeem and Pofale 2012]. No investigation on utilization of this material as coarse aggregate in concrete has been carried out yet in Bangladesh as a replacement of brick coarse aggregate. Therefore, this study has been planned to find out the suitability of utilization of the slag aggregates in concrete. Partial replacement of brick aggregate was not conducted in this study. Also, studies on utilization of processed slag as fine aggregate in concrete and flue dust for making controlled low strength materials will be conducted later.

Table 1. Physical Properties of Coarse Aggregates

\begin{tabular}{|l|c|c|c|c|c|}
\hline \multicolumn{1}{|c|}{ Type of Aggregate } & $\begin{array}{c}\text { Specific } \\
\text { Gravity in SSD } \\
\text { Condition }\end{array}$ & $\begin{array}{c}\text { Absorption } \\
\text { Capacity (\%) }\end{array}$ & $\begin{array}{c}\text { SSD Unit } \\
\text { Weight }\left(\mathrm{kg} / \mathrm{m}^{3}\right)\end{array}$ & $\begin{array}{c}\text { Abrasion } \\
(\%)\end{array}$ & FM \\
\hline SL (Slag-Lightweight) & 2.24 & 2.7 & 1122 & 45.9 & 6.75 \\
\hline SH (Slag-Heavyweight) & 3.54 & 1.93 & 2480 & 15.8 & 6.75 \\
\hline SM (Slag-Mixed) & 2.67 & 2.57 & 1550 & 35.2 & 6.75 \\
\hline BC (Brick Chips) & 2.30 & 14.8 & 1236 & 38.3 & 6.75 \\
\hline
\end{tabular}

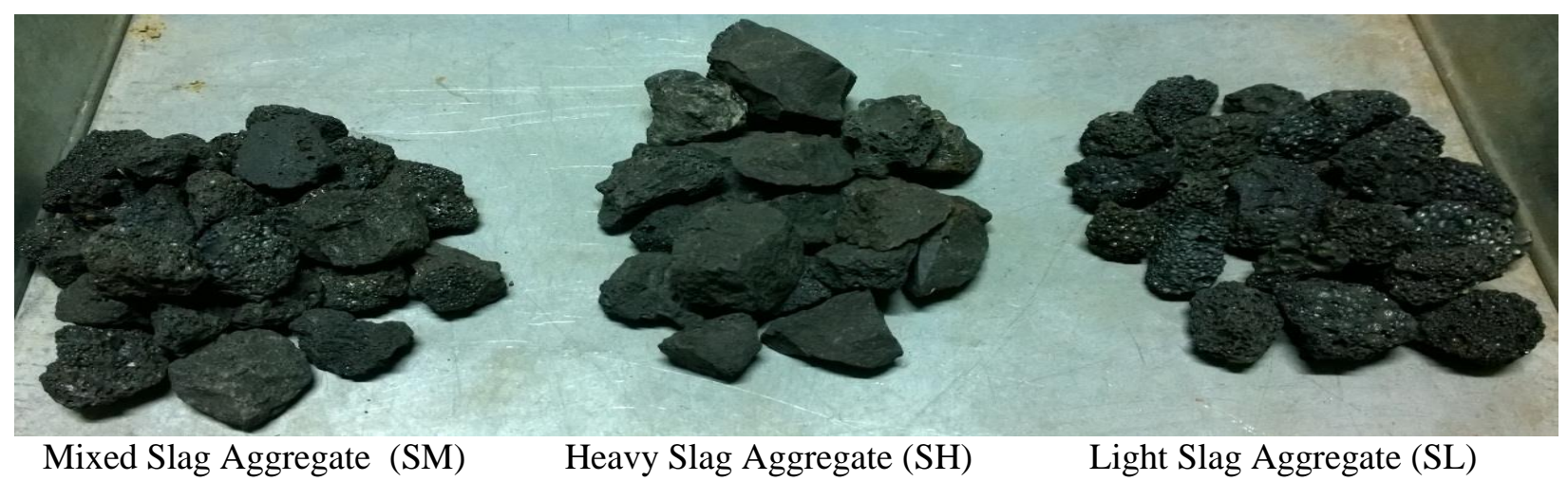

Figure 1. Different Types of Slag Aggregates (SM, SH, and SL) 

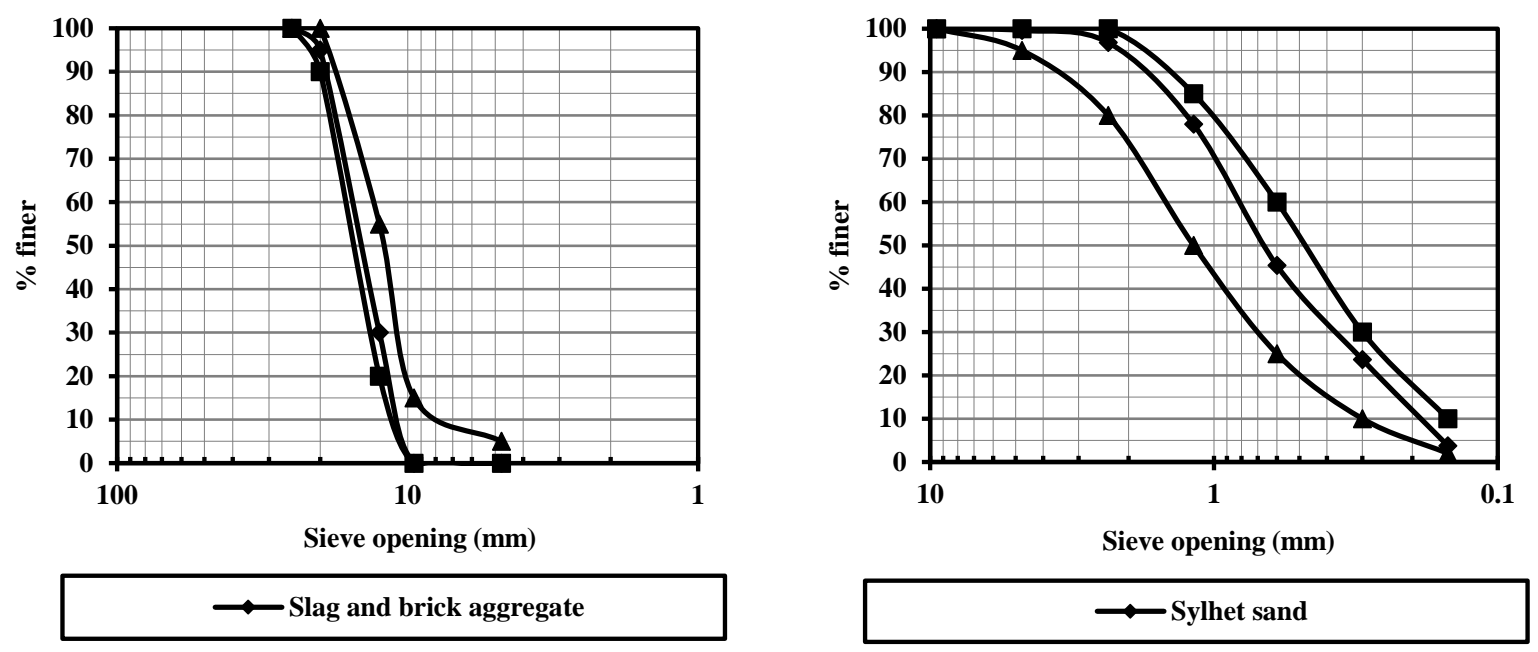

\section{Figure 2. Grading Curve of Aggregates (Left - Coarse Aggregates, Right- Fine Aggregate)}

\section{EXPERIMENTAL METHOD}

Slag aggregate sample was collected from the crushing plant of steel slag of a local steel manufacturing company. It was found that some slag aggregates were light in weight with a lot of voids and some were heavier with a little or no voids. Therefore, the slag aggregates were separated into three types, such as lightweight slag aggregate (SL), heavyweight slag aggregate $(\mathrm{SH})$, and mixed slag aggregate (SM). Different types of slag aggregates are shown in Figure 1. At the laboratory, large sized slag aggregates were broken into smaller sizes manually. The slag aggregate was tested for grading, unit weight, abrasion, specific gravity and absorption capacity and abrasion as per ASTM standards. The maximum size of slag aggregate was $20 \mathrm{~mm}$. The grading curves of coarse and fine aggregates are shown in Figure 2. The properties of different coarse aggregates are summarized in Table 1. Natural river sand was used as fine aggregate. The specific gravity, absorption capacity, fineness modulus, and unit weight of the sand were $2.52,3.3 \%, 2.52$, and $1520 \mathrm{~kg} / \mathrm{m}^{3}$ respectively. The grading curves of coarse and fine aggregates satisfy the requirement of ASTM C33 as shown in Figure 2. CEM Type II/A-M cement (as per BDS EN 197-1:2000) was used. The maximum amount of mineral component in the cement was $20 \%$. Tap water was used for mixing and curing of concrete. For comparison with slag aggregate, first class brick aggregate was also investigated as control aggregate. The physical properties of slag and brick aggregates are compared later.

Cylindrical samples $(100 \mathrm{~mm} \times 200 \mathrm{~mm})$ were made with different sand to aggregate (s/a) volume ratios $(0.36,0.40$, and 0.44$)$; W/C $(0.45,0.50,0.55)$ and cement contents $\left(351 \mathrm{~kg} / \mathrm{m}^{3} ; 372 \mathrm{~kg} / \mathrm{m}^{3}\right.$, and $\left.395 \mathrm{~kg} / \mathrm{m}^{3}\right)$. The coarse aggregates were $100 \%$ slag aggregate or $100 \%$ brick aggregate. In this study, partial replacement of brick aggregate by slag aggregate was not considered. Eleven different cases were investigated for slag aggregate and five different cases were investigated for brick aggregate. The mixture proportions are summarized in Table 2 and Table 3 for slag and brick aggregates respectively. The notations used for the cases are explained at the bottom of each table. Also, concrete specimens were made with volumetric mixture proportions, such as 1:1.5:3 (Coarse Aggregate : Fine Aggregate : Cement) and 1:2:4; which are commonly used volumetric mix proportions in Bangladesh. A total of 82 concrete specimens were made with slag aggregate and 52 concrete specimens were made with brick aggregate. 
Table 2. Mixture Proportion of Concrete Made with Slag Aggregates

\begin{tabular}{|c|c|c|c|c|c|c|}
\hline \multirow[t]{2}{*}{ Designation } & \multirow[t]{2}{*}{$\mathbf{W} / \mathbf{C}$} & \multirow{2}{*}{$\begin{array}{l}\text { s/a } \\
(\%)\end{array}$} & \multicolumn{4}{|c|}{ Unit Content $\left(\mathrm{kg} / \mathrm{m}^{3}\right)$} \\
\hline & & & $\begin{array}{l}\text { Cement } \\
\text { (C) }\end{array}$ & Water $(\mathbf{W})$ & $\begin{array}{c}\text { Fine } \\
\text { Aggregate } \\
\text { (FA) }\end{array}$ & $\begin{array}{c}\text { Coarse Aggregate } \\
\text { (CA) }\end{array}$ \\
\hline SL-45-36-395 & 0.45 & 36 & 395 & 178 & 588 & 955 \\
\hline SL-50-36-372 & 0.50 & 36 & 372 & 186 & 588 & 955 \\
\hline SL-55-36-351 & 0.55 & 36 & 351 & 193 & 588 & 955 \\
\hline SM-50-40-372 & 0.50 & 40 & 372 & 186 & 652 & 1066 \\
\hline SH-50-40-372 & 0.50 & 40 & 372 & 186 & 652 & 1414 \\
\hline SM-50-44-372 & 0.50 & 44 & 372 & 186 & 718 & 995 \\
\hline SH-50-44-372 & 0.50 & 44 & 372 & 186 & 718 & 1320 \\
\hline SM-1:1.5:3 & 0.50 & \multicolumn{5}{|c|}{ Volume based mixed design. $\mathrm{CA}: \mathrm{FA}: \mathrm{C}=1: 1.5: 3$. } \\
\hline SH-1:1.5:3 & 0.50 & \multicolumn{5}{|c|}{ Volume based mixed design. CA : FA : $\mathrm{C}=1: 1.5: 3$. } \\
\hline SM-1:2:4 & 0.50 & \multicolumn{5}{|c|}{ Volume based mixed design. CA : FA : $\mathrm{C}=1: 2: 4$. } \\
\hline SH-1:2:4 & 0.50 & \multicolumn{5}{|c|}{ Volume based mixed design. CA : FA : $\mathrm{C}=1: 2: 4$. } \\
\hline \multicolumn{7}{|c|}{$\begin{array}{l}\text { Notations: } \mathrm{SL} \text { - Lightweight slag, } \mathrm{SH}-\text { Heavyweight slag, } \mathrm{SM}-\text { Mixed slag, B - Brick, } \mathrm{CA}-\text { Coarse } \\
\text { aggregate, FA - Fine aggregate, } \mathrm{C}-\mathrm{Cement}, \mathrm{W} / \mathrm{C}-\mathrm{Water} \text { to cement ratio, s/a - sand to total aggregate } \\
\text { volume ratio; The first two digits indicate } \mathrm{W} / \mathrm{C} \text {, the second two digits indicate sand to aggregate } \\
\text { volume ratio in } \% \text {, and the last three digits indicate cement content in } \mathrm{kg} / \mathrm{m}^{3} \text {. }\end{array}$} \\
\hline
\end{tabular}

Table 3. Mixture Proportion of Concrete Made with Brick Aggregates

\begin{tabular}{|l|c|c|c|c|c|c|}
\hline \multirow{2}{*}{ Designation } & \multirow{2}{*}{ W/C } & s/a (\%) & $\begin{array}{c}\text { Cement } \\
(\mathbf{C})\end{array}$ & $\begin{array}{c}\text { Water } \\
(\mathbf{W})\end{array}$ & $\begin{array}{c}\text { Fine } \\
\text { Aggregate } \\
\text { (FA) }\end{array}$ & $\begin{array}{c}\text { Coarse Aggregate } \\
\text { (CA) }\end{array}$ \\
\hline B-45-36-395 & 0.45 & 36 & 395 & 178 & 588 & 980 \\
\hline B-50-36-372 & 0.50 & 36 & 372 & 186 & 588 & 980 \\
\hline B-55-36-351 & 0.55 & 36 & 351 & 193 & 588 & 980 \\
\hline B-50-40-372 & 0.50 & 40 & 372 & 186 & 652 & 919 \\
\hline B-50-44-372 & 0.50 & 44 & 372 & 186 & 718 & 857 \\
\hline
\end{tabular}

After mixing concrete, slump was measured and then concrete specimens were made as per ASTM C31M03. Ultrasonic pulse velocity (UPV) was measured by using Pundit (UPV meter) according to ASTM C 597-02. Then the specimens were crushed by a compression machine. Stress versus strain data were recorded during compression test. The specimens were tested at 7, 28, 60 and 90 days for compressive strength, tensile strength, stress-strain curve and modulus of elasticity. The fractured surfaces of the specimens were examined carefully after crushing of the cylinder specimens.

\section{RESULTS AND DISCUSSIONS}

Physical properties of slag aggregates. The physical properties, such as specific gravity, absorption capacity, abrasion, and fineness modulus (FM) of both slag and brick aggregates are summarized in Table 1. The specific gravity of the lightweight slag (SL) aggregate was very similar to the brick aggregate (BC). 
The mixed slag aggregate (SM) gives similar specific gravity as found for stone chips and the heavyweight slag gives specific gravity much higher than the brick aggregate as well as stone aggregate. This variation is mainly because of the cooling process of slag aggregate where the outer portion of slag pot is rapidly cooled with water which makes the slag spongy and soft at the outside. Inner portion of the slag pot cools down slowly by air thus forming a much harder and denser structure. Also, the iron content may vary in different slag aggregates. Further studies are required to find out their chemical compositions. The absorption capacity of slag aggregate is much lower than the absorption capacity of brick aggregate. Compared to the lightweight slag aggregate, heavyweight slag aggregate gives relatively lower absorption capacity. The abrasion value of lightweight slag aggregate was $45.9 \%$ and the same for brick aggregate was $38.3 \%$. It is understood that the lightweight slag aggregate is relatively softer than the brick aggregate investigated in this study. The same value for the heavyweight and mixed slag aggregate was $15.8 \%$ and $35.2 \%$ respectively. The heavyweight slag aggregate gives a very low abrasion value which is even much lower than the stone aggregates (varied from 20\% to 35\%) used in Bangladesh.

Surface texture and physical appearance. The closer views of different slag aggregates (SL, SH, SM) are shown in Figure 1. The surface texture of the slag aggregate was rough compared to the brick aggregate. Appearance of voids is seen in lightweight slag aggregate. Heavyweight slag aggregates were found denser than the SL and SM.

Chemical composition. Based on the analysis of chemical composition of furnace slag, it is found that furnace steel slag is composed of mainly silicon oxide (average 55\%), iron oxide (average 15\%), and manganese oxide (average 10\%) with some other minor components.

Workability of concrete. As shown in Figure 3, for concrete made with slag aggregate (SL, SM, and SH), the workability is much higher than the similar concrete made with brick aggregate. It is expected due to the less water absorption capacity of slag aggregate compared to the brick aggregate. The workability of concrete made with SL is the highest compared to SM and SH. SH shows the lowest slump compared to SL and SM. From the variation of workability with the change of s/a ratio, it is found that with the increase of s/a ratio, workability is reduced. It is clearly revealed that the concrete made with slag aggregate has better workability compared to the similar concrete made with brick aggregate.

Unit weight of concrete. The unit weight of concrete is shown in Figure 4 for concrete made with brick aggregate and different slag aggregates. Concrete made with slag aggregate (particularly for SM and SH) shows more unit weight compared to the similar concrete made with brick aggregate. It is due to greater specific gravity of the slag aggregate (SM or $\mathrm{SH}$ ) compared to the brick aggregate. The unit weight of concrete made with $\mathrm{SH}$ is about $2500 \mathrm{~kg} / \mathrm{m}^{3}$. The same for $\mathrm{SL}$ and $\mathrm{SM}$ is varied from $2200 \mathrm{~kg} / \mathrm{m}^{3}$ to 2300 $\mathrm{kg} / \mathrm{m}^{3}$.

Compressive strength. The gain of strength of concrete made with slag aggregate and conventional brick aggregate is shown in Figure 5. From Figure 5, it is evident that the rate of gain of strength of slag aggregate concrete is much higher than that of concrete made with brick aggregate, specially, beyond 60 days. The variation of compressive strength of concrete with the change of type of coarse aggregates and other parameters is shown in Figure 6. Concrete made with SH gives the highest compressive strength compared to the other slag and brick aggregates. Concrete made with SL gives lower compressive strength. However, concrete made with SM and SH show higher compressive strength compared to the similar concrete made with brick aggregate.

It is understood that lighter portion of slag aggregate (SL) is to be reduced to improve the compressive strength of concrete made with slag aggregate. Irrespective of the types of aggregate, it is found that with the increase of s/a ratio, the compressive strength of concrete is increased. By using $\mathrm{SH}$, it is possible to make concrete of compressive strength $34.77 \mathrm{MPa}$ and $30.83 \mathrm{MPa}$ for volumetric mix proportion of 1:1.5:3 and 1:2:4 (W/C=0.50) respectively. The same values for slag aggregate of type SM become 20.23 MPa and 
16.63 MPa for 1:1.5:3 and 1:2:4 volumetric mix proportions respectively. It is also understood that the concrete made with the mixed slag aggregate (SM) gives similar or better compressive strength compared to the concrete made with brick aggregate.

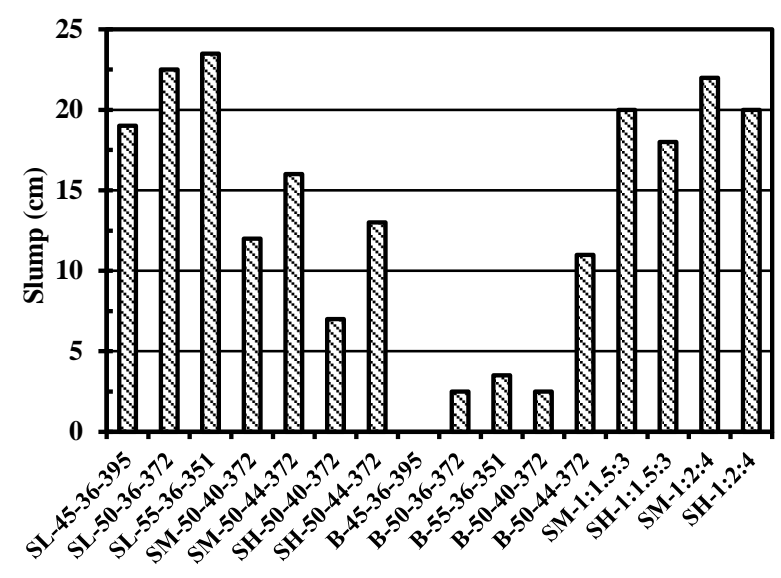

Figure 3. Workability of Concrete

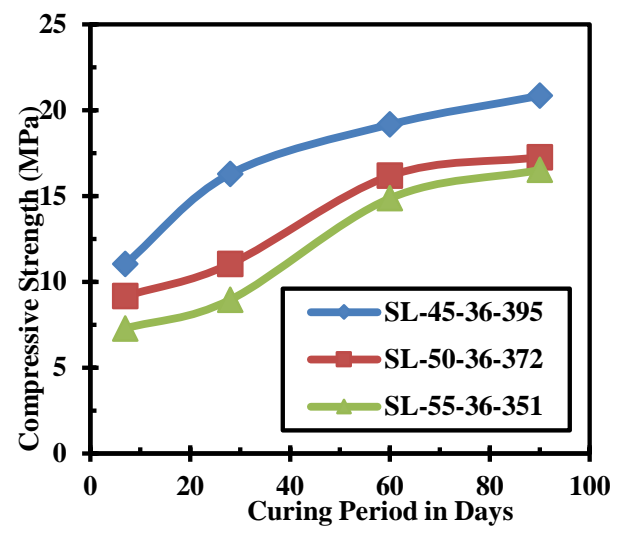

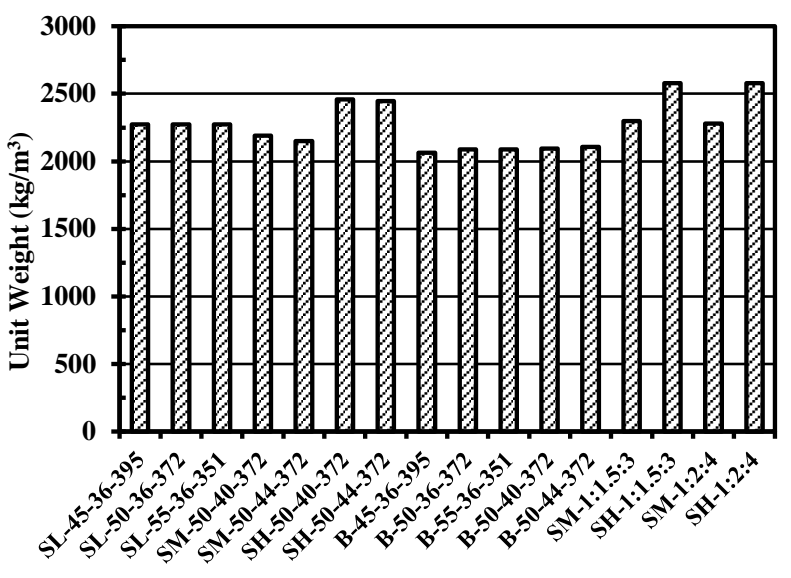

Figure 4. Unit Weight of Concrete

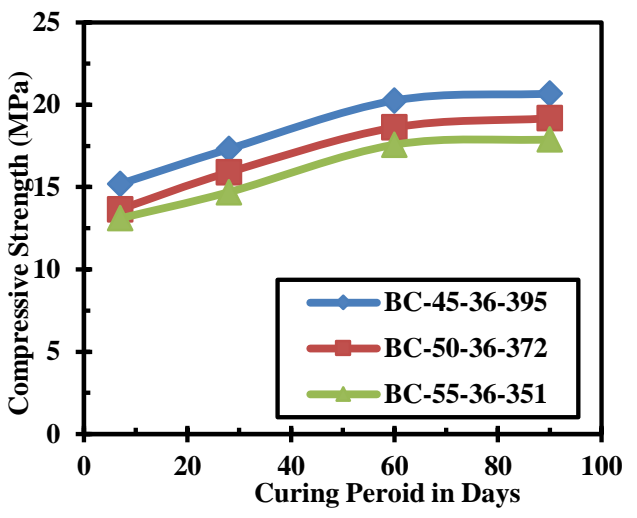

Figure 5. Compressive Strength of Concrete Over Time

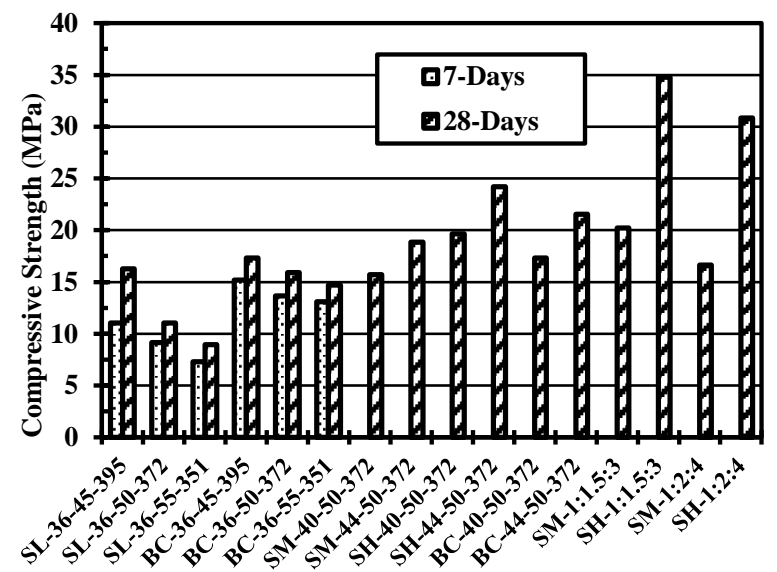

Figure 6. Compressive Strength of Concrete

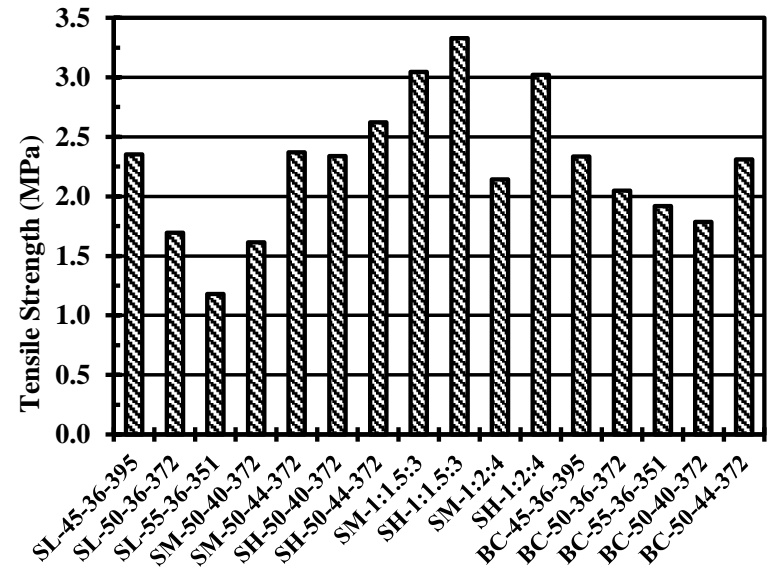

Figure 7. Tensile Strength of Concrete 
Tensile strength. The variation of tensile strength of concrete with the change of type of coarse aggregates and other parameters is shown in Figure 7. Concrete made with SL shows lower tensile strength compared to brick aggregate, however concrete made with SM and SH show higher tensile strength compared to brick aggregate. Relationship between tensile strength and compressive strength is proposed later.

Ultrasonic pulse velocity (UPV). The variation of UPV with the change of type of coarse aggregates and other parameters is shown in Figure 8. It is found that the ultrasonic pulse velocity in concrete made with slag aggregate is higher than the concrete made with brick aggregate. Concrete made with heavyweight slag aggregate $(\mathrm{SH})$ gives more velocity compared to the concrete made with other types of aggregates (SL, $\mathrm{SM}$, and $\mathrm{BC})$.

Modulus of elasticity of concrete. The modulus of elasticity of concrete was calculated from the stressstrain curves. The results are shown in Figure 9. Due to the steeper stress-strain curve at the beginning of loading for concrete made with lightweight slag aggregate (SL), more modulus of elasticity is found for concrete made with lightweight slag aggregate compared to the concrete made with other slag aggregates and brick aggregate.

Fractured surfaces of concrete after crushing. The fractured surfaces of concrete after crushing specimens are shown in Figure 10. For lightweight slag aggregate concrete, the failure surfaces cross through the aggregate, however for mixed (SM) or heavyweight $(\mathrm{SH})$ slag aggregate failure surfaces cross around the aggregate. It indicates that it will be possible to increase compressive strength of concrete further for heavyweight or mixed slag aggregates.

Relationship between modulus of elasticity and compressive strength of concrete. The variation of modulus of elasticity and square root of compressive strength of concrete is shown in Figure 11. The following relationships are proposed between modulus of elasticity (Ec) and compressive strength of concrete $\left(\mathrm{f}_{\mathrm{C}}^{\prime}\right)$ made with different slag aggregates and brick aggregate:

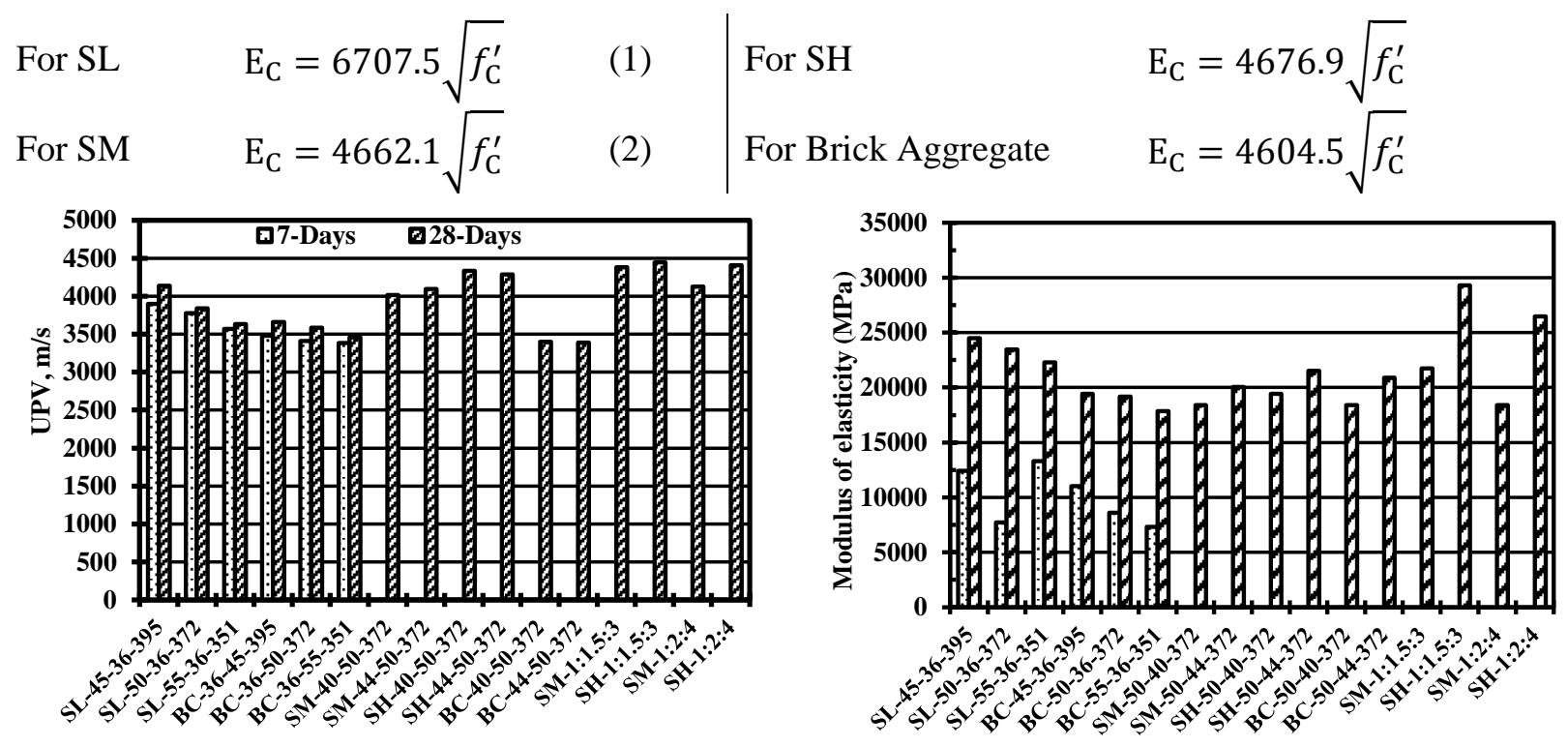

Figure 8. Ultrasonic Pulse Velocity

Figure 9. Modulus of Elasticity of Concrete 


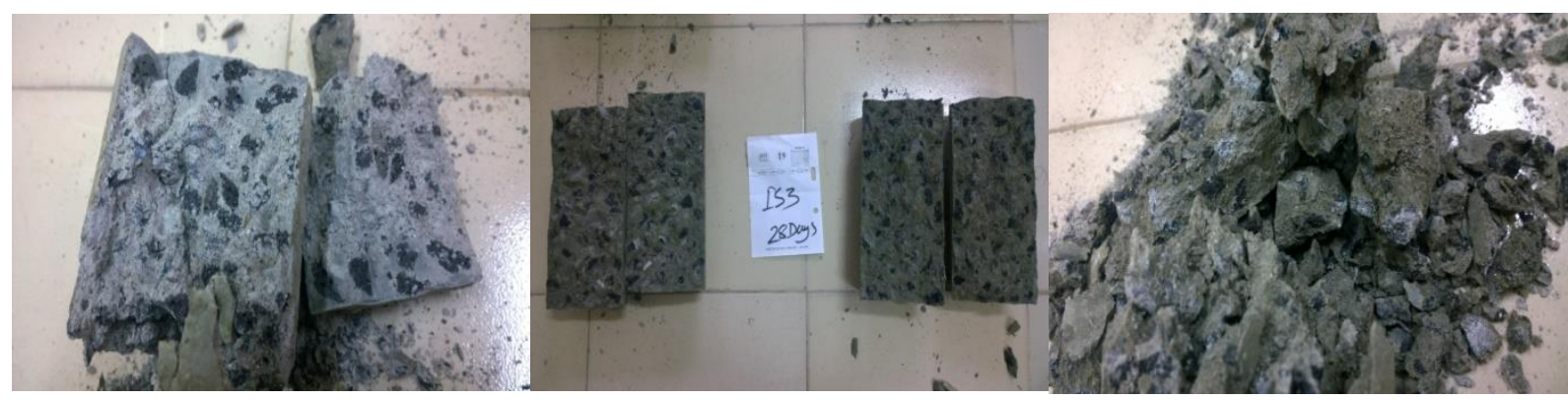

Figure 10. Fracture Surfaces of Concrete
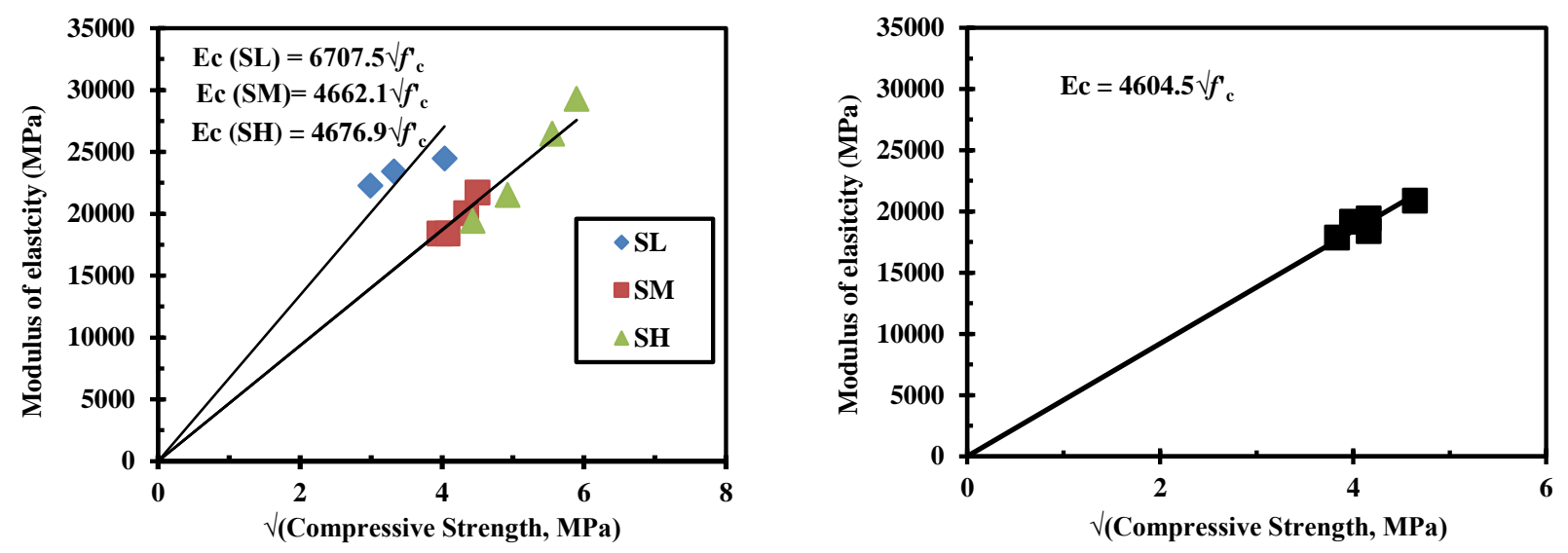

Figure 11. Relationship between Modulus of Elasticity and Compressive Strength (Left Slag Aggregate (SL, SM, and SH), Right - Brick Aggregate)
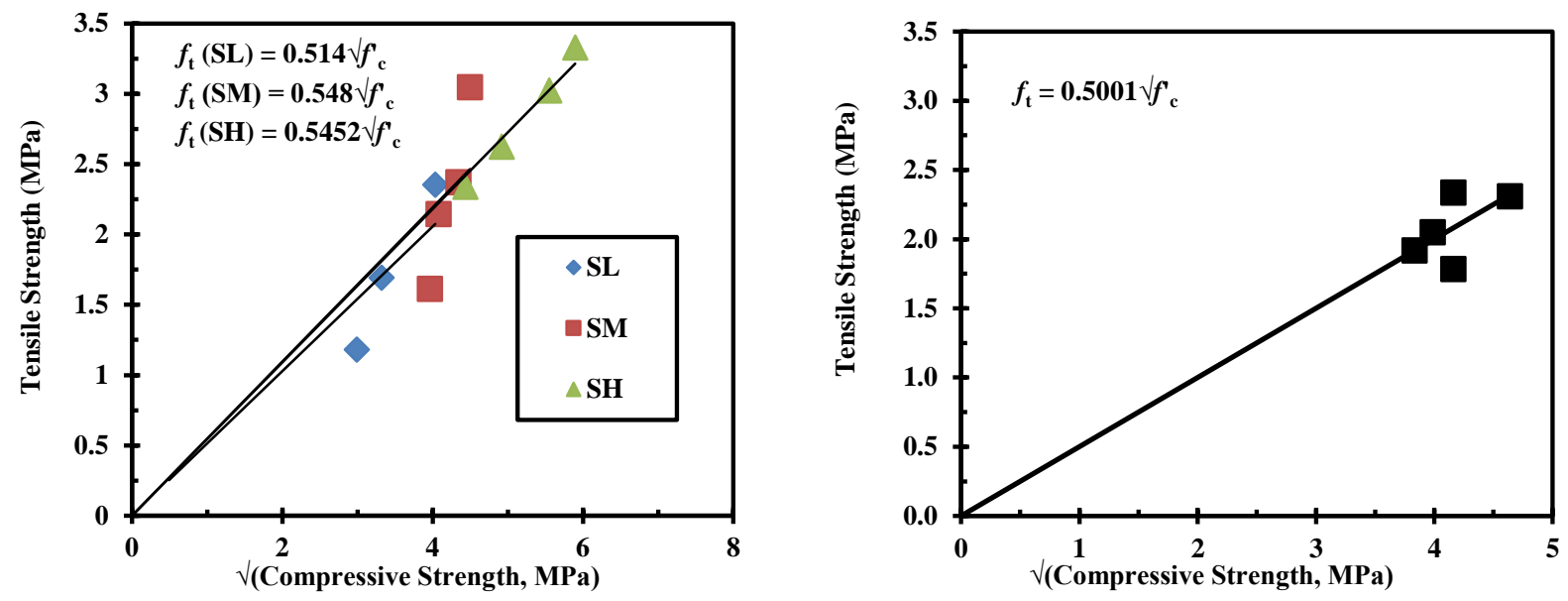

Figure 12. Relationship between Tensile Strength and Compressive Strength (Left - Slag Aggregate (SL, SM and SH), Right - Brick Aggregate) 
It is found that for the same strength of concrete, the modulus of elasticity is higher for concrete made with slag aggregate compared to brick aggregate. Further investigations are necessary to find out the reasons behind the significant increase in modulus of elasticity of concrete made with SL.

Relationship between tensile strength and compressive strength. The variation of tensile strength of concrete with square root of compressive strength of concrete is shown in Figure 12. As shown in Figure 12 , the following relationships are proposed between tensile strength $\left(\mathrm{f}_{\mathrm{t}}\right)$ and compressive strength $\left(\mathrm{f}_{\mathrm{C}}^{\prime}\right)$ of concrete made with different slag aggregates and brick aggregate:

$$
\begin{array}{lll|ll}
\text { For SL } & f_{\mathrm{t}}=0.5140 \sqrt{f_{\mathrm{C}}^{\prime}} & \text { (5) } & \text { For SH } & f_{\mathrm{t}}=0.5452 \sqrt{f_{\mathrm{C}}^{\prime}} \\
\text { For SM } & f_{\mathrm{t}}=0.5480 \sqrt{f_{\mathrm{C}}^{\prime}} & \text { (6) } & \text { For Brick Aggregate } & f_{\mathrm{t}}=0.5001 \sqrt{f_{\mathrm{C}}^{\prime}}
\end{array}
$$

It is found that for the same compressive strength of concrete, the tensile strength of concrete is higher for concrete made with slag aggregate (particularly for $\mathrm{SM}$ and $\mathrm{SH}$ ) compared to the concrete made with brick aggregate.

\section{CONCLUSION}

Based on the results of this experimental investigation on utilization of steel slag in concrete as coarse aggregate, the following conclusions are drawn:

1. The absorption capacity of steel slag aggregate is much lower than that of brick aggregate,

2. The specific gravity of lightweight slag aggregate is similar to the brick aggregate, however the heavier slag aggregate and mixed slag aggregate show more specific gravity than brick aggregate,

3. The workability of concrete made with slag aggregate is higher than that of concrete made with brick aggregate,

4. The modulus of elasticity and tensile strength of concrete made with slag aggregate is higher than the same for similar concrete made with brick aggregate,

5. For similar grade of concrete, the UPV through concrete made with slag aggregate is faster than the concrete made with brick aggregate,

6. By using mixed slag aggregate, it is possible to produce $16.63 \mathrm{MPa}$ and $20.23 \mathrm{MPa}$ concrete with 1:2:4 and 1:1.5:3 volumetric mixture proportions $(\mathrm{W} / \mathrm{C}=0.5)$ respectively. The same for heavyweight slag aggregate becomes $30.83 \mathrm{MPa}$ and $34.77 \mathrm{MPa}$ for 1:2:4 and 1:1.5:3 volumetric mixture proportions respectively, and

7. Relationships between compressive strength of concrete and tensile strength of concrete, and compressive strength and modulus of elasticity of concrete are proposed for concrete made with different slag aggregates. The relationships are varied with the change of type of slag aggregates.

\section{ACKNOWLEDGEMENT}

The authors acknowledge the financial support provided by the Bangladesh Steel Re-Rolling Mills Limited (BSRM) to conduct this study. The authors also acknowledge the laboratory and other associated facilities provided by the Department of Civil and Environmental Engineering, Islamic University of Technology (IUT), Gazipur to carry out this study. 


\section{REFERENCES}

ASTM C 33, "Standard Specification for Concrete Aggregates." ASTM International, West Conshohocken, PA.

ASTM C 31, "Standard Practice for Making and Curing Concrete Test Specimens in the Filed." ASTM International, West Conshohocken, PA.

ASTM C 597. "Standard Test Method for Pulse Velocity Through Concrete", ASTM International, West Conshohocken, PA.

Dieu, G. J. D., Lunagaria, H. M., Rashid, R. (2015), "A Review of Use of Steel Slag in Concrete Mixes for Rigid Pavement", International Journal of Engineering and Research Development, 2(3), 78-86.

Kothai, P. S., Malathy, R.(2013), "Enhancement of Concrete Properties by Steel Slag as a Partial Replacement Material for Coarse Aggregate", Australian Journal of Basic and Applied Sciences. 7(12), 278-285.

Maslehuddin, M., Alfarabi, M., Sharif, M., Shameem, M., Ibrahim, M., Barry, M. S. (2003), "Comparison of Properties of Steel Slag and Crushed Limestone Aggregate Concrete", Journal of Construction and Building Materials, 17 (2), 105-112.

Mohammed, T. U., Hasnat, A., Awal, M. A., Bosunia, S. Z. (2015), "Recycling of Brick Aggregate Concrete as Coarse Aggregate", Journal of Materials in Civil Engineering, ASCE.27 (7).doi: http://dx.doi.org/10.1061/(ASCE)MT.1943-5533.0001043.

Nadeem, M., Pofale, A. D. (2012), "Experimental Investigation of Using Slag as an Alternative to Normal Aggregates (Coarse and Fine) in Concrete",. International Journal of Civil and Structural Engineering. 3(1). 117-127.

Sandhu R. S., Singh, J., Dhanoa, G. S. (2015), "Use of Air Cooled Blast Furnace Slag (ACBFS) as Coarse Aggregates - A Case Study". International Journal of Innovations in Engineering Research and Technology (IJIERT). 2(4), 1-10.

Yi, H., Xu, G., Cheng, H., Wang, J., Wan, Y., Chen, H. (2012), "An Overview of Utilization of Steel Slag",. Procedia Environmental Sciences, ICWMT 7, 16, 791-801. 